\title{
Connecting STEM Scholars with Employers Worldwide
}

\section{Melissa Gavin, University of Wisconsin,Platteville}

After graduating from the University of Wisconsin-Madison, Gavin worked for a government research nonprofit and since obtaining her master's degree has worked for a variety of nonprofits in various roles. Currently, she is the Special Projects Coordinator for the Distance Learning Center at the University of Wisconsin-Platteville. Gavin also teaches MEDIA 3010/5010 Business Communication and APC 3300 Technical and Professional Communication.

\section{Lisa Naderman, University of Wisconsin, Platteville}

Lisa Naderman graduated from the University of Wisconsin-Platteville in 2014 with a Masters of Science in Project Management through distance learning. She began her career at UW-Platteville working in Prospective Student Services as a recruiter, while taking on the roles of assistant women's basketball coach and associate lecturer for the Health and Human Performance Department. Naderman is currently working in the Distance Learning center as an advisor for the undergraduate programs and student services coordinator. Naderman's responsibilities include providing support for student services, working with assessments of student services in online programs and also oversees the NSF STEM Master Scholar Program. 


\section{Connecting STEM Scholars with Employers Worldwide}

\section{Abstract}

STEM career opportunities are plentiful worldwide; however, students are not always able to find those opportunities due to location, time constraints, and other barriers. A significant component and goal of the 2015 National Science Foundation S-STEM grant received was to develop a program that increases career exploration opportunities for scholars who are from underrepresented populations in STEM fields. With entering grant year three, scholars are graduating with their master's degree and are seeking advanced STEM career placement. By implementing a virtual career fair, access to the career exploration process increases for students including the STEM Master Scholars.

The University of Wisconsin-Platteville holds a traditional career fair targeting students in STEM fields with nearly 100 STEM employers participating. STEM Master Scholars are limited to attending traditional career fairs located near them since these students are distributed across the United States while they complete their degrees online. In addition, barriers such as the space limitations and travel costs of a traditional career fair can leave interested employers without a booth and an opportunity to meet with students. With the opportunity of a virtual career fair, STEM Master Scholars will be able to receive similar services to on-campus students and employers will have the opportunity to meet with students.

Virtual career fairs provide an opportunity to students in any online program worldwide. A virtual career fair allows students to connect with employers whom the students may not be able to engage with due to previously mentioned limitations. Primary research shows that companies have attended virtual career fairs in the past.

The inaugural virtual career fair, which will be open to all campus students including the STEM Master Scholars will be held in spring 2018. Prior to the virtual career fair, the STEM Master Scholars will attend a professional development opportunity online to help them successfully navigate and professionally interact within a virtual career fair. Topics to be covered in this opportunity include resume preparation, career fair etiquette, and online interview practice.

This poster session will highlight the preparation and results of the inaugural virtual career fair by showcasing a variety of assessment metrics such as participation analytics of both the student and employer use of the event, qualitative data from both students and employers, as well as feedback from staff coordinating the event.

\section{Literature Review/Need for Virtual Career Fair}

Traditional career fairs are face-to-face, enabling students to meet many employers in one day, and virtual career fairs (VCFs), enable students to meet many employers in one day using technology. Both options offer students and employers the ability to network. However, each 
type of fair has limitations and advantages. Understanding the limitations and advantages of each event helps show why a VCF is an important addition for students and employers alike - and in some cases, it may even be the ideal option.

Most notably, traditional career fairs require a substantial cost and time commitment [1],[2].

VCFs reduce both time and costs for employers. In a study conducted by Galanaki [2], the author noted that cost effectiveness of recruiting online was both a critical factor and an influencer. Other critical factors included a wide response rate, specific niche, and passive job seekers [2]. While VCFs may not be free, the VCF environment reduces travel costs for both employers and students since both parties are able to attend with a viable internet connection.

VCFs allow for a broader pool of applicants than a traditional fair due to the environment. Galanaki [2] found that being able to reach passive job seekers and individuals globally were both benefits of a VCF. While Galanaki [2] noted that web-based recruiting was "not [the] first option yet" as a limitation, Frank and Taylor [3] argued that "web recruiting is exploding" since it "offered a way to attack time, cost and reach simultaneously." In addition to being able to reach a wide spread audience, a VCF allows for niche fairs [2], [3].

While VCFs use web-based platforms instead of a face-to-face meeting, platforms allow employers and students to perform similar functions. To replace a face-to-face interview or meeting, employers may meet with students using chat rooms or video conferencing [4]. In addition to performing similar functions, research shows that the two fairs may complement one another. Both Miller [4] and Leece [1] acknowledge that offering both fairs is a benefit for employers and students.

History

The University of Wisconsin-Platteville enrolled student population consists of both on-campus and online students, with approximately $20 \%$ of the student body enrolled solely online. Historically, career services have been offered to students attending class on-campus; these services include resume reviews, mock interviews, interview etiquette, and career fairs. In 2014 online students were provided the same access to these services. One service that has always been available to all students, regardless of an on-campus or online affiliation, are the career fairs.

The Career and Professional Development Office (CPDO) hosts a fall and spring traditional career fair. Online students have been encouraged to attend the traditional career fairs, though due to travel restrictions and distances, most have not participated. In addition to limitations on travel, traditional career fairs also faced space limitations with meeting the maximum number of employers since 2015. Each year additional employers expressed interest but were turned away due to space limitations. Knowing the limitations facing the traditional career fair, the CPDO and our office partnered to design a virtual career fair. Coordinators of the VCF leaned on a niche market created by an established engineering program and S-STEM grant awards when developing the VCF. 
Process of Developing a Virtual Career Fair (VCF)

Implementing a VCF can vary based on the target market. Thus, careful research on various types of VCFs and campus needs is a necessity. Initially, a committee was formed to determine the wanted outcomes of the VCF. We determined the main outcomes to be an ease of use for all stakeholders, including students, employers, and campus parties; an affordable system that offered options; and accessible customer service.

After determining the main outcomes, research was conducted on vendors to decide who would assist with hosting the VCF. In addition to the outcomes listed above, we also reviewed the technology offered within the platforms such as hosting rights and computer requirements. The last item that was researched was which vendors other universities and colleges were using. At the end of the research, three companies were identified that could provide the necessary services.

When determining which company to use, the committee met with the individual companies for demonstrations of event platforms. After meeting with each company and asking additional questions, the committee chose the desired company and platform. Initially, the company contracted was not considered due to lack of information about the company-even though the committee's research showed that it was the most used company by other campuses.

After negotiating terms, the process to implement the VCF began. The committee was provided with a list of needs, such as logos and branding information, from the vendor. One advantage to working with the vendor was the ease of use; the vendor offers full customer service by working directly with the employers to set up the event including payments and building the virtual booths.

Once the VCF was established, marketing plans to recruit employers and students were established by the committee. In addition to contacting alumni, the committee also used an established database of employers from the CPDO. Many of these employers already attend the traditional career fair and have an understanding of the enrolled students. Regardless of campus affiliation, students enrolled in a STEM degree and alumni of those programs were invited to participate in the VCF.

Add-on Items

After the framework of the event was created, the committee decided it was important to educate students on VCF etiquette since this is a newer concept. As part of the S-STEM grant, Students in the NSF S-STEM Scholar Masters program participate in monthly Scholar Spots, a one hour professional development opportunity. The Scholar Spot hosted by CPDO focused on VCF etiquette - reviewing aspects such as web cam etiquette, online chat room expectations, and resume tips. With each Scholar Spot, students are encouraged to be engaged and ask questions. Students attending the Scholar Spot are required to provide feedback on the session. Results from the feedback indicated most NSF scholarship recipients had not attended a VCF before, so 
the etiquette session was beneficial to helping prepare the students. When asked about their expectations for the event, feedback varied as this experience was new to them.

\section{Results}

With offering our first VCF, the committee was unsure what to expect, so the goal was to host the event using a cost-recovery model. To reach cost recovery, 15 employers had to register for the VCF. Regarding costs, the committee did not have a goal in place for the expected number of students and alumni to attend since it was assumed students would attend. After experiencing the first VCF, the committee realized some false assumptions about the attendance of both the employers and the students/alumni.

Employer results. Employer recruitment started in December, after a vendor was secured. Recruitment of employers happened in three ways:

1. Alumni of STEM programs were solicited.

2. The Vendor solicited to its list of STEM employers.

3. The CPDO office solicited to its STEM employers.

The recruitment for employers utilized e-mail and social media. More than 11,000 emails were sent to potential employers or employees of potential employers. On average $20 \%$ of the emails were opened. In addition, the social media post had a reach of 1,064 with 53 post clicks and 8 shares; compared to other posts on that social media site, this was one of the top 10 posts of the year.

With the goal of 15 employers attending the VCF, the actual number of employers registered was 12; however, 32 representatives from the 12 companies attended the career fair. Assessments are currently being completed on how to improve employer numbers for a future VCF by reaching out to employers as to why they did not attend.

Even though the number of employers may have been less than expected, valuable information was gained from the employers who did attend. A survey was completed by company representatives after the VCF closed. The results varied greatly, particularly from one company, where two representatives from one company responded with mixed results. However, the feedback left by these representatives provided insight into what the committee needs to consider when hosting the next VCF.

Both representatives indicated that this was the first time either had attended a virtual career fair and that neither would attend in the future. The main concerns from the representatives were in regards to the system and not having the appropriate information available. The committee reviewed the results and determined this issue would be simple to overcome with additional training for the companies, especially for first time companies attending a VCF. However, both representatives noted that one benefit of the VCF was being able to work while attending the VCF. 
Participant results. Current students and alumni from STEM-related fields were invited to participate in the VCF. Advertising for the event started two weeks prior to the VCF. The committee chose to start the formal advertising at the on-campus career fair as the target audience was likely to attend the on-campus career fair.

A mixed method approach was used for the student and alumni marketing. Tools used included:

1. Direct emails to the students and alumni of the target audience.

2. Handouts distributed in class by faculty of STEM-related programs.

3. Posters hung around campus.

4. Direct emails and 1 hour information session to NSF STEM Scholars

Approximately 10,000 invitations were sent via email or handed out by faculty and staff. Of the nearly 7,000 emails sent approximately $23 \%$ were opened. Of the nearly 8,000 alumni and students invited to participate in the VCF, 109 registered. Nearly $30 \%$ of these participants were students enrolled solely online.

Participants also completed a survey after the event. Of the 109 registered participants, 7 completed the survey. All respondents acknowledged that this was their first time attending a VCF. Unlike employer feedback, student feedback was positive. Most students would be willing to participate in another VCF and found the experience to be satisfactory. The overall benefit seen by participants was being able to connect with employers virtually.

\section{Outcomes}

While the event did not meet the goal of 15 employers, the committee learned a lot throughout the process. The partnership between the two divisions - Distance Learning and CPDO - is needed to make the event successful through the strengths and resources each area brings to the planning of the VCF.

In addition to the successful collaboration, future items to be addressed by the committee for the next VCF offering include:

1. Timing of the event; the event was hosted in the spring. However, the CPDO received feedback from both students and employers that the best time for hiring is in the fall. During the fall, students and employers are making hiring decisions for future permanent employment and summer internships. Thus, the committee is exploring the option of the event occurring in the fall.

2. Advertising to both employers and participants; the recruitment strategy will be analyzed to find the best method to increase participation from both the employers and the students. This may require more lead time during the recruitment of both parties. The main concern is not taking away from the on-campus career fair, but rather adding value by supplementing with a VCF.

\section{References}


[1] R. Leece, “A virtual careers fair,” Australian Journal of Career Development, vol. 14, no. 2, pp.34-39, Winter 2005.

[2] E. Galanaki, "The decision to recruit online: a descriptive study," Career Development International, vol. 7, no. 4, pp. 243-251, 2002.

[3] F. Frank and C. Taylor, "Talent management: Trends that will shape the future," Human Resource Planning, vol. 27, no. 1, pp. 33-41, 2004.

[4] K. Miller and R. McDaniels, "Cyberspace, the new frontier," Journal of Career Development, vol. 27, no. 3, pp. 199-206, Spring 2001. 